\title{
Educação Ambiental e Apropriação de Valores: um Diálogo Possível na Educação Infantil
}

\section{Environmental Education and Value Appropriation: a Possible Dialogue in Child Education}

\author{
Cristiane Magalhães Bissaco
}

Centro Universitário Toledo. SP, Brasil.

E-mail: cristianemagalhaes@yahoo.com.br.

Recebido em: 08/04/19; Aceito em: 14/08/19

\begin{abstract}
Resumo
Partindo do entendimento de que a Educação Ambiental deve ser uma prática intencionalizada e coerente, este trabalho se propõe a realizar uma revisão bibliográfica que articule o campo teórico da Educação Ambiental com o da Educação Infantil, a fim de observar os limites e as possibilidades da prática docente ao tratar da construção ou apropriação de valores. Assim, os seguintes questionamentos norteiam a pesquisa: que práticas docentes podem ser identificadas em relação à apropriação de valores? Elas abarcam a temática ambiental? Em que contextos são pesquisadas? A Educação Infantil é um desses contextos? Para tal discussão foram levantados nove artigos internacionais, que levam o leitor a compreender que as práticas docentes em relação aos valores ensinados são distintas de um artigo para outro: sendo dois deles como prática moral, três como construção, dois como socialização, um como formação de hábitos e um como clarificação. Apenas dois dos artigos não abarcam a temática ambiental. Em relação ao contexto de pesquisa, neste levantamento os artigos estão assim distribuídos: cinco destinados à Infância - Educação Básica, um trata da Educação básica com adolescentes e três destinados ao Ensino Superior. Portanto, concluiu-se que a Educação Infantil é um dos contextos em que a Educação Ambiental tem sido pesquisada, principalmente, no que se refere à apropriação de valores pertinentes à temática ambiental.
\end{abstract}

Palavras-chave: Educação Moral. Meio Ambiente. Infância.

\begin{abstract}
Based on the understanding that Environmental Education should be an intentional and coherent practice, this paper proposes to perform a literature review that articulates the theoretical field of Environmental Education with that of Early Childhood Education, in order to observe the limits and possibilities of teaching practice, when dealing with the value construction or appropriation. Thus, the following questions guide the research: What teaching practices can be identified in relation to the values appropriation ? Do they cover the environmental theme? In what contexts are they researched? Is early childhood education one of these contexts? For this discussion nine international articles were raised, which lead the reader to understand that teaching practices in relation to the values taught are distinct from one article to another: two of them as moral practice, three as construction, two as socialization, one as habits formation and one as clarification. Only two of the articles do not cover the environmental theme. Regarding the research context, in this survey the articles are directed to: five for Childhood Basic Education, one for Basic Education with adolescents and three for Higher Education. Therefore, it was concluded that early childhood education is one of the contexts in which environmental education has been researched, especially regarding the appropriation of values relevant to the environmental theme.
\end{abstract}

Keywords: Moral Education. Environment. Childhood.

\section{Introdução}

Grandes são os esforços para compreender a atual crise que permeia as relações entre os humanos e entre estes e a natureza, a fim de se pensarem propostas que conduzam à melhora da qualidade de vida de todos os seres do Planeta. Fala-se em uma crise que vai muito além do "ambiental" e que abarca, sobretudo, questões sociais, valorativas e até mesmo civilizatórias. É neste cenário que a Educação tem sido assinalada como um dos possíveis caminhos de enfrentamento - pelo seu potencial transformador, o que justifica a necessidade de investimentos no campo de pesquisa da área. Diversos autores argumentam sobre a urgência de esses estudos proporcionarem a reflexão necessária para o exercício da criticidade e da criatividade na construção de significados sobre o mundo, sobre a temática ambiental e sobre o processo educativo.

Nesse sentido, os dados obtidos por Carvalho (2010) permitem apontar áreas silenciadas nos trabalhos apresentados no EPEA - Encontro de Pesquisa em Educação Ambiental, quais sejam, processos formativos para o trabalho com a temática ambiental voltada para a Educação Infantil e para a Educação de Jovens e Adultos. Embora não seja objetivo desta pesquisa observar as questões formativas de professores/ educadores, em uma perspectiva ambiental, os apontamentos de Carvalho (2010) fazem intuir que há também escassez na produção acadêmica voltada para o entrelaçamento entre Educação Ambiental e Educação Infantil.

Cabe informar que as Diretrizes Curriculares Nacionais para a Educação Infantil - Resolução CNE/CEB n ${ }^{\circ}$ 5, de 17 de 
dezembro de 2009 em seu artigo $3^{\circ}$ concebe "o Currículo da Educação Infantil como um conjunto de práticas que buscam articular as experiências e os saberes das crianças com os conhecimentos que fazem parte do patrimônio cultural, artístico, ambiental, científico e tecnológico", de forma que se promova seu desenvolvimento integral (BRASIL, 2009). Isto é, por meio deste documento, que possui caráter mandatório, há uma orientação para que o patrimônio ambiental seja articulado com as crianças da Educação Infantil. Cabe ressaltar ainda que este documento orienta a política de formação de professores e a política de planejamento e avaliação na Educação Infantil e é isso que se pretende com esta pesquisa, verificar práticas educacionais organizadas, intencionalmente planejadas e permanentemente avaliadas, o que também é proposto por Carvalho (2006), pois a Educação Ambiental deve ser uma "prática intencionalizada e coerente".

Carvalho (2006) afirma que o trabalho com a Educação Ambiental deve contemplar três dimensões: conhecimento, valores éticos e estéticos e a participação política, o que comunga diretamente com as Diretrizes (BRASIL, 2009), já que em seu artigo $6^{\circ}$ ficam evidentes os princípios norteadores das propostas pedagógicas de Educação Infantil, sendo esses: a) éticos (autonomia, responsabilidade, cooperação, respeito ao bem comum, ao meio ambiente, às diferentes culturas, identidades e singularidades), b) políticos (direitos de cidadania, exercício da criticidade, respeito à ordem democrática) e c) estéticos (sensibilidade, criatividade, liberdade de expressão nas diferentes manifestações artísticas e culturais).

Assim, este estudo objetivou articular o campo teórico da Educação Ambiental com a Educação Infantil, a fim de observar os limites e possibilidades da prática docente ao tratar da apropriação de valores, cabendo apontar os questionamentos que norteiam este trabalho: que práticas docentes podem ser identificadas em relação à apropriação de valores? Elas abarcam a temática ambiental? A Educação Infantil é um dos contextos em que são pesquisadas?

\section{Desenvolvimento}

\subsection{Metodologia}

A fim de identificar os significados oriundos de práticas docentes que envolvem a temática ambiental, em especial, que discutem valores em contexto de Educação Infantil, esta revisão bibliográfica foi direcionada metodologicamente pelos preceitos da pesquisa qualitativa. Assim, em um primeiro momento, foram selecionados artigos que se destinavam a discutir o tema de interesse, embora não tenha sido possível localizar os três grupos temáticos em produções únicas Valores, Educação Infantil e Educação Ambiental. Por esse motivo, cada um dos temas foi priorizado, em diferentes momentos, com o intuito de que servissem de norteadores da pesquisa. Em um segundo momento, foram identificadas as ideias centrais de cada artigo, para, finalmente, ser sistematizado o arcabouço teórico, o caminho metodológico e os resultados obtidos em cada um dos trabalhos selecionados, atrelando-os, em especial, aos conceitos levantados por Puig (1998) em relação às práticas de educação moral.

Ao realizar a primeira busca na base de dados Periódicos Capes, utilizou-se o termo em inglês Good Human Beings. Entre os periódicos detectados nesta procura, o que mais atendia aos interesses foi Early Childhood Research \&Practice, o que levou a uma nova busca dentro do mesmo Periódico, desta vez com o termo: Early Childhood Program. Selecionou-se um resultado relevante: "Bowne e Brokmeier. At the Zoo: Kindergartners Reinvent a Dramatic Play Area".

Ainda na base Periódicos Capes, buscou-se o termo em língua inglesa Environmental Education for Children. Entre os periódicos apontados nesta busca há destaque para International Electronic Journal of Environmental Education e The International Journal of Environmental and Science Education. Selecionou-se um artigo: "Yardimci e Leblebicioglu. The effect of a nature camp on children's conceptions of nature".

Ao buscar na base de dados da CAPES pelo termo em língua espanhola: educación moral, se obteve como resultado um artigo relevante localizado no periódico Teoría de la Educación - Revista Interuniversitaria:" SorianoDíaz. Los caminos de la educación civico-moral - Un debate permanente".

Além disso, no segundo momento da pesquisa, acessouse a Base de dados Emerald, buscando por values education, somente em periódicos, tendo noventa e três resultados. Os periódicos que emergiram nesta pesquisa foram: International Journal of Sustainability in Higher Education, Young Consumers: Insight and Ideas for Responsible Marketers, Journal of Educational Administration e Educational Research (áreas contempladas: Ensino Superior, Publicidade, Administração). Cabe ressaltar que muitos dos artigos relacionados a essa entrada de busca estão associados à área administrativa/econômica e não à educação, como objetivado neste trabalho. Por isso, dos noventa e três artigos, somente três foram selecionados para a leitura e análise: "El-Bassiouny e Abou-Aish. An empirical assessment of the relationship between character/ethics education and consumer behavior at the tweens segment: the case of Egypt", "Muijen. Integrating value education and sustainable development into a Dutch university curriculum" e "Cotton. Teaching controversial environmental issues: neutrality and balance in the reality of the classroom".

Ainda na Base de dados Emerald se utilizou o termo values in environmental education nos títulos dos artigos e surgiram cinco ocorrências. Três desses são do periódico International Journal of Sustainability in Higher Education, um deles do Young Consumers: Insight and Ideas for Responsible Marketers e outro é do Campus-Wide Information Systems. Tratam de trabalhos com temáticas que envolvem a educação a 
distância ou do Ensino Superior e, por isso, foram descartados.

O termo em língua inglesa taxonomy in environmetal education não apresentou resultados. Já com a combinação dos termos Environmental education + values + Primary School, os resultados apontados já haviam aparecido anteriormente.

Em língua espanhola, o termo "educación en valores" com aspas não apresentou resultados. Já, sem aspas foram encontrados dois resultados nos periódicos International Journal of Sustainability in Higher Education e Tourism Review. Também o termo de busca "Educación ambiental en valores" com aspas não apresentou resultados. Sem aspas foi encontrado um resultado já apresentado anteriormente, destinado ao Ensino Superior.

Finalmente, no terceiro momento de buscas se utilizou a base de dados ERIC com o termo children environmental education. Por ser um termo muito amplo surgiram 8.454 resultados e, por isso, passou-se a utilizar filtros com a finalidade de diminuir o número de resultados. Assim, se a busca estivesse destinada somente aos periódicos acadêmicos haveria uma queda dos resultados para 3.426.

Entre os periódicos apontados nesta busca se deu destaque para: Early Childhood Education Journal, Journal of Environmental Education, Cambridge Journal of Education. Dos 40 primeiros artigos identificados foi selecionado um desses que correspondia ao interesse dessa busca para a leitura na íntegra: "Mehmet. The Effects of Ecology-Based Summer Nature Education Program on Primary School Students' Environmental Knowledge, Environmental Affect and Responsible Environmental Behavior".

Refinando a busca para as publicações entre os anos 2010 e 2013, os resultados caíram para 803. Um dos periódicos apontados e que foi selecionado para este levantamento é o Educational Sciences: Theory and Practice.

Ainda na base de dados Eric foi realizada a busca com o termo values on education, obtendo como resultado 59.111 artigos. Como o termo não direcionava diretamente à Educação Ambiental, alterou-se o termo de busca para values on environmental education, havendo 2.377 resultados. A fim de refinar a busca se alterou o tipo de fonte para periódico acadêmico, e o número foi reduzido para 1.086 resultados. Também como filtro foi selecionado o assunto environmental education e foram obtidos 418 resultados. Entre essses, publicados entre os anos 2010 a 2013, resultaram 129 resultados. Por se tratar de um número muito amplo se decidiu restringir a busca para o termo moral on environmental education, que trouxe como resultados 34 artigos acadêmicos. Assim, os trabalhos selecionados foram dos periódicos: International Journal of Sustainability in Higher Education e Journal of College Student Development do qual foram selecionados dois artigos: "falseMayhew, Seifert e Pascarella. How the First Year of College Influences Moral Reasoning Development for Students in Moral Consolidation and Moral Transition" e "Mulder. Don't preach. Practice! Value laden statements in academic sustainability education".
Desse modo, foram elencados deste levantamento oito artigos em língua inglesa e um em língua espanhola, totalizando nove trabalhos com a finalidade de detectar que autores teóricos os fundamentam, que percursos metodológicos são apontados e mais, quais resultados são evidenciados por meio de cada um dos artigos previamente selecionados.

No Quadro 1 os artigos levantados de maneira sintetizada. Quadro 1 - Artigos com dados da publicação e objetivos de pesquisa

\begin{tabular}{|c|c|c|}
\hline Título do Artigo & $\begin{array}{c}\text { Periódico - Ano - } \\
\text { Local }\end{array}$ & Objetivos \\
\hline $\begin{array}{l}\text { An empirical } \\
\text { assessment of } \\
\text { the relationship } \\
\text { between character/ } \\
\text { ethics education and } \\
\text { consumer behavior at } \\
\text { the tweens segment: } \\
\text { the case of Egypt. }\end{array}$ & $\begin{array}{l}\text { Young Consumers, } \\
\text { 2011. Egito. }\end{array}$ & $\begin{array}{c}\text { Propor a educação } \\
\text { do caráter como } \\
\text { uma solução } \\
\text { potencial para } \\
\text { as preocupações } \\
\text { crescentes sobre } \\
\text { o consumismo } \\
\text { infantil. }\end{array}$ \\
\hline $\begin{array}{c}\text { Integrating } \\
\text { value education } \\
\text { and sustainable } \\
\text { development } \\
\text { into a Dutch } \\
\text { university } \\
\text { curriculum. }\end{array}$ & $\begin{array}{l}\text { International } \\
\text { Journal of } \\
\text { Sustainability in } \\
\text { Higher Education, } \\
\text { 2004. Holanda }\end{array}$ & $\begin{array}{c}\text { Descrever um } \\
\text { estudo piloto com } \\
\text { foco nos processos } \\
\text { de aprendizagem } \\
\text { envolvidos na } \\
\text { educação de } \\
\text { valores e a questão } \\
\text { de como uma } \\
\text { perspectiva ética } \\
\text { da sustentabilidade } \\
\text { pode estar } \\
\text { integrada ao } \\
\text { currículo. }\end{array}$ \\
\hline $\begin{array}{c}\text { The Effects of } \\
\text { Ecology-Based } \\
\text { Summer Nature } \\
\text { Education Program } \\
\text { on Primary } \\
\text { School Students' } \\
\text { Environmental } \\
\text { Knowledge, } \\
\text { Environmental Affect } \\
\text { and Responsible } \\
\text { Environmental } \\
\text { Behavior }\end{array}$ & $\begin{array}{c}\text { Kuram ve } \\
\text { Uygulamada } \\
\text { Egitim Bilimler, } \\
\text { 2011. Turquia. }\end{array}$ & $\begin{array}{c}\text { Avaliar os efeitos } \\
\text { do programa } \\
\text { de Educação } \\
\text { Natural baseada } \\
\text { em Ecologia no } \\
\text { conhecimento, } \\
\text { afeto ambiental e } \\
\text { comportamento } \\
\text { ambiental } \\
\text { responsável de } \\
\text { Alunos da Escola } \\
\text { Primária. }\end{array}$ \\
\hline $\begin{array}{l}\text { How the First Year } \\
\text { of College Influences } \\
\text { Moral Reasoning } \\
\text { Development for } \\
\text { Students in Moral } \\
\text { Consolidation and } \\
\text { Moral Transition. }\end{array}$ & $\begin{array}{c}\text { Journal of } \\
\text { College Student } \\
\text { Development, } \\
\text { 2012, Estados } \\
\text { Unidos. }\end{array}$ & $\begin{array}{c}\text { Investigar } \\
\text { o impacto } \\
\text { diferencial de } \\
\text { experiências dos } \\
\text { universitários de } \\
\text { primeiro ano no } \\
\text { desenvolvimento } \\
\text { de raciocínio } \\
\text { moral. }\end{array}$ \\
\hline $\begin{array}{l}\text { Don't preach. } \\
\text { Practice! Value } \\
\text { laden statements } \\
\text { in academic } \\
\text { sustainability } \\
\text { education. }\end{array}$ & $\begin{array}{c}\text { International } \\
\text { Journal of } \\
\text { Sustainability in } \\
\text { Higher Education, } \\
2010, \\
\text { Europa. }\end{array}$ & $\begin{array}{c}\text { Discutir se os } \\
\text { professores } \\
\text { universitários } \\
\text { devem pregar/ } \\
\text { transferir valores } \\
\text { e quais afirmações } \\
\text { de valor são } \\
\text { aceitáveis e quais } \\
\text { não são. }\end{array}$ \\
\hline
\end{tabular}




\begin{tabular}{|c|c|c|}
\hline $\begin{array}{c}\text { Teaching } \\
\text { controversial } \\
\text { environmental } \\
\text { issues: neutrality and } \\
\text { balance in the reality } \\
\text { of the classroom }\end{array}$ & $\begin{array}{l}\text { Educational } \\
\text { Research, 2006, } \\
\text { Inglaterra. }\end{array}$ & $\begin{array}{c}\text { Fornecer uma } \\
\text { perspectiva } \\
\text { alternativa no } \\
\text { ensino de questões } \\
\text { ambientais } \\
\text { controversas, } \\
\text { investigando } \\
\text { crenças e práticas } \\
\text { docentes. }\end{array}$ \\
\hline $\begin{array}{c}\text { At the Zoo: } \\
\text { Kindergartners } \\
\text { Reinvent a } \\
\text { Dramatic Play } \\
\text { Area. }\end{array}$ & $\begin{array}{l}\text { Early Chilhood } \\
\text { Research \& } \\
\text { Practice, } 2008 . \\
\text { Estados Unidos. }\end{array}$ & $\begin{array}{l}\text { Construir um } \\
\text { “zoológico na sala } \\
\text { de aula" por meio } \\
\text { do faz de conta, } \\
\text { incorporando } \\
\text { informações } \\
\text { sobre os animais } \\
\text { e zoológicos } \\
\text { que as crianças, } \\
\text { e professores } \\
\text { pesquisaram. }\end{array}$ \\
\hline $\begin{array}{l}\text { The Effect of a } \\
\text { Nature Camp } \\
\text { on Children's } \\
\text { Conceptions of } \\
\text { Nature. }\end{array}$ & $\begin{array}{c}\text { International } \\
\text { Electronic Journal } \\
\text { of Environmental } \\
\text { Education. } 2012 . \\
\text { Turquia. }\end{array}$ & $\begin{array}{c}\text { Oferecer } \\
\text { oportunidades } \\
\text { de aprendizagem } \\
\text { autêntica para } \\
\text { crianças, em } \\
\text { acampamentos, } \\
\text { visando ampliar } \\
\text { a concepção } \\
\text { da natureza das } \\
\text { crianças. }\end{array}$ \\
\hline $\begin{array}{l}\text { Los caminos de la } \\
\text { educación cívico- } \\
\text { moral - Un debate } \\
\text { permanente }\end{array}$ & $\begin{array}{c}\text { Teoría de la } \\
\text { Educación } \\
\text { - Revista } \\
\text { Interuniversitaria. } \\
2007, \\
\text { Espanha. }\end{array}$ & $\begin{array}{l}\text { Defender uma } \\
\text { proposta de } \\
\text { educação ética } \\
\text { desde uma } \\
\text { perspectiva } \\
\text { integral. }\end{array}$ \\
\hline
\end{tabular}

Fonte: Dados da pesquisa.

\subsection{Discussão}

É importante destacar que a pesquisa realizada em cursos de pós-graduação na área de Educação, de acordo com Macedo e Sousa (2010), vem se consolidando, o que pode ser observado, entre outros fatores, pelo aumento na procura nas agências de fomento.

O que se tem hoje em termos de organização da pósgraduação em Educação é um modelo mais flexível que, de certa forma, retoma "as ideias de interdisciplinaridade, flexibilidade e integração ensino-pesquisa, produto de uma redefinição da área sobre os sentidos da ideia de linhas de pesquisa" (MACEDO; SOUSA, 2010, p.170).

Payne (2009) levanta três questionamentos a partir da diversidade encontrada em pesquisas da área de Educação Ambiental: a) as inúmeras versões educacionais (pedagogias, currículos) para a EA podem comprometer sua validade? b) as discussões realizadas por países de língua inglesa são relevantes para o contexto brasileiro? e c) é possível chegar a um senso comum (elementos comuns, um mínimo de consenso) nessa diversidade que a área apresenta? E propõe que diante desse quadro seja pensado um caminho de sistematizar a área em uma construção mais sólida, decorrendo dessa discussão o conceito de enquadramento, ou seja, a produção intelectual conceituada, contextualizada, representada e legitimada.

Para este estudo, os artigos selecionados se pautam, especificamente, em propostas de ensino-aprendizagem que, além de discutir temas ambientais, se apoiam em uma perspectiva de desenvolvimento moral. Em alguns casos, em contexto específico de educação para crianças e, em outros casos, em contextos como o Ensino Superior que foram de grande valia para entender como as propostas são implementadas, que objetivos visavam atender, seu referencial teórico/metodológico e os resultados obtidos. Todas essas informações serão apresentadas na sequência.

Pautado no conceito de Educação Natural - em que há o entendimento de que a criança deve ser levada ao ambiente natural e envolvida em atividades ao ar livre para maior desenvolvimento de conhecimentos, de afeto ambiental e de comportamento ambiental responsável - o objetivo do artigo (3) proposto por Mehmet (2011) foi avaliar os efeitos do programa de Educação Natural baseada em Ecologia, realizado no verão de 2008 na Turquia. Tal programa dispunha de doze dias e os sujeitos focais da pesquisa somavam um total de 64 alunos de Escola Primária.

Esse estudo de caráter quali-quantitativo e concebido como experimental, contando com instrumentos de coleta de dados, tanto no início do programa (pré-teste) como ao fim (pós-teste), com o intuito de avaliar nos estudantes seus conhecimentos, sua relação de afeto e seu comportamento responsável em relação ao meio ambiente. Os dados revelaram que o programa de educação natural de base ecológica contribuiu, significativamente, para o desenvolvimento de um comportamento ambiental responsável nas crianças. Embora o conhecimento ambiental do pós-teste dos alunos e o grau de afeto tenham sido mais elevados que os do préteste, nenhum efeito significativo do programa de educação sobre o conhecimento ambiental e afeto foram observados. Cabe informar que ainda que o artigo não traga em si a discussão sobre o desenvolvimento do caráter ou formação moral, ou seja, o entendimento de que o sujeito se desenvolve a partir da exposição a um programa de educação natural esse leva a interpretar que o desenvolvimento de afetividade aqui é entendido como proveniente de um mecanismo de socialização, em que valores e normas "são impostos com uma força alheia" à consciência e à vontade do indivíduo (PUIG, 1998, p. 29).

Muito similar à pesquisa de Mehmet (2011) se encontra a de Yardimci e Leblebicioglu (2012), por ambas as pesquisas tratarem a questão da Educação Natural na Turquia, isto é, uma Educação baseada na experiência com a natureza. Esta última (8) investigou vinte e quatro alunos da $4^{\mathrm{a}}$ e $5^{\mathrm{a}}$ séries (9 meninas e 15 meninos) em um acampamento natural, que oferece oportunidades de aprendizagem concreta para crianças. O programa de acampamento começou com as observações na floresta e possibilitou que as crianças discutissem suas 
observações com seus amigos e cientistas. Um questionário foi aplicado no início e outro ao fim do acampamento. Os resultados mostraram que o programa foi capaz de ampliar a concepção de natureza das crianças, incluindo seres vivos e não-vivos, tratando também das questões estéticas e afetivas em relação à natureza, porém de uma maneira a ser interiorizada, adaptada e reprodutiva, posto que é o programa responsável em transmitir esses valores. Na perspectiva de educação moral, como socialização, "os sujeitos recebem da sociedade o sistema de valores e normas vigentes" (PUIG, 1998, p.29).

O terceiro artigo (2) aqui discutido é o de Muijen (2004) que, por meio de um referencial teórico pautado na fenomenologia, descreve um estudo piloto com foco nos processos de aprendizagem envolvidos na educação de valores e a questão de como uma perspectiva filosófica e ética da sustentabilidade pode estar integrada ao currículo. A autora explica que o Esnino Superior na Holanda apresenta dominante abordagem tecnológica da ciência nos currículos acadêmicos, entretanto a Universidade em que a pesquisa se desenvolveu tem como missão um ideal pedagógico de "formação acadêmica ampla", orientado para educar os alunos para que se tornem "cientistas e profissionais moralmente responsáveis e reflexivos". O estudo sugere que os alunos precisam de mais conhecimento no campo dos valores, e que diferente dos dados empíricos é preciso aprender também por meio da intuição, da reflexão e da comunicação.

Muijen (2004) se valeu de um modelo de aprendizagem baseado em dilemas sequenciados por quatro fases: a) fase intuitiva: os alunos leem um estudo de caso envolvendo dilemas e intuitivamente escolhem ações para essa situação específica, formulando os argumentos e valores morais subjacentes a sua escolha; b) aquisição de conhecimento: os alunos estudam conjuntos relevantes de conhecimento, e podem fazer outra opção e oferecer uma explicação de seus valores, em seguida, eles discutem entre si sobre suas escolhas; c) reflexão sobre conjuntos relevantes de conhecimento: os alunos refletem sob uma perspectiva filosófica, em seguida, eles refazem suas escolhas, apresentam os seus argumentos e clarificam seus valores, também nesta fase, eles discutem suas escolhas e valores uns com os outros, e d) reflexão sobre o processo de aprendizagem: os alunos refletem sobre suas escolhas e fazem uma descrição verbal do seu processo de aprendizagem. O que se intenciona por meio dessa metodologia é propiciar uma comunicação dialógica e uma reflexão sobre questões morais, principalmente, no que dizem respeito ao desenvolvimento sustentável.

Por meio dessas leituras se pode inferir que o trabalho aqui apresentado se insere em uma perspectiva de educação moral como clarificação de valores (PUIG, 1998, p.39), apresentando como pressuposto teórico que os conflitos de valor só podem ser solucionados por meio de uma "decisão subjetiva do indivíduo neles implicado", desconsiderando assim uma perspectiva social, o que pode, inclusive, resultar em uma defesa do individualismo.

O artigo (1) de El-Bassiouny e Abou-Aish (2011), resultado de estudo realizado no Egito com crianças de oito a doze anos, focou mudanças no comportamento do consumidor pela educação do caráter. Concebido como um estudo empírico pioneiro se valeu de uma metodologia qualiquantitativa, testando quatro variáveis: estilo de consumo, liderança de opinião, humanitarismo e etnocentrismo.Os resultados mostraram uma diferença global significativa entre o comportamento do consumidor dos grupos de teste e de controle. Assim, a pesquisa indicou que crianças expostas à educação de caráter estão propensas a apresentar consumo ético, bem como uma maior inclinação para a responsabilidade social corporativa.

A partir dessas leituras voltadas para a construção da personalidade moral, pode-se indicar que a pesquisa acima apresentada se pauta em uma concepção de educação moral como desenvolvimento cognitivo e evolutivo (PUIG, 1998, p.44), entendendo "que o domínio progressivo das formas de pensamento é um valor desejável em si mesmo e que leva cada vez mais para juízos otimizados e valiosos" e desconsiderando assim fatores motivacionais, condutuais, bem como as diferenças individuais imbricadas no desenvolvimento moral.

Nessa esteira de entendimento moral como desenvolvimento cognitivo e evolutivo, o artigo (4) de Mayhew, Seifert e Pascarella (2012), realizado nos Estados Unidos, objetivou retratar uma investigação sobre o impacto diferencial de experiências dos universitários de primeiro ano no desenvolvimento de raciocínio moral de 1.469 estudantes, por meio de exposição a dilemas morais, classificando-os em: estágio de transição moral (mais influenciados pelo ambiente universitário) e estágio de consolidação moral (menos influenciados pelo ambiente universitário).

Os autores afirmam que o Ensino Superior tem priorizado a educação moral, por meio de cobranças de seus estudantes em relação ao desenvolvimento do caráter, da consciência, da cidadania e da civilidade, da tolerância, bem como da responsabilidade, tanto individual como social. Apoiados na teoria kohlberguiana observaram, em sua pesquisa, que conforme os indivíduos progridem pelos estágios do desenvolvimento moral, o senso de justiça sai de um patamar egocêntrico (pré-convencional) para o patamar social, visando "o maior bem para o maior número de pessoas" (pósconvencional) (PUIG, 1998, p.60).

Mayhew, Seifert e Pascarella (2012) demonstraram como resultados de pesquisa que os ganhos de desenvolvimento em raciocínio moral variaram em função dos estágios morais dos alunos, de modo que alguns estudantes podem estar mais prontamente desenvolvidos para enfrentar e resolver os desafios educacionais que, frequentemente, caracterizam os programas e currículos de primeiro ano. Com base em Puig (1998) se entende o propósito da educação como algo que 
transcenda à mera transmissão de informação moral, ou seja, que consista "em estimular os educandos a atingir os estágios seguintes de desenvolvimento moral".

O trabalho (5) de Mulder (2010) questionou o slogan: "Pratique o que você prega", em especial, para as universidades que ensinam o desenvolvimento sustentável (SD), já que estes institutos devem aplicar princípios do desenvolvimento sustentável para sí, por exemplo, no próprio campus, na compra verde, entre outros. O desenvolvimento sustentável consta de dois elementos principais: a responsabilidade com as gerações futuras e com os menos favorecidos. Discute também que os professores universitários não devem pregar valores, ou seja, não devem transferir valores para os seus alunos pela autoridade de sua posição, seus argumentos não precisam ser convincentes, necessitam simplesmente propiciar que seus alunos construam seus próprios argumentos.

Diante disso, traz como questão: quais afirmações de valor são aceitáveis e quais não são? Argumenta-se que a formação acadêmica em desenvolvimento sustentável deve visar esclarecer questões morais e ajudar os alunos a desenvolverem as suas próprias posições morais diante dos valores que estão presentes no trabalho dos profissionais. Desse modo, o artigo apresenta os resultados de uma pesquisa realizada com 42 professores universitários de desenvolvimento sustentável internacional em cursos de Engenharia, em sua maioria europeus, sobre a aceitabilidade de declarações carregadas de valor.

Além disso, o trabalho compara estes resultados com uma sondagem realizada entre engenheiros e estudantes de engenharia (civil e mecânica). Conclui-se que os professores de desenvolvimento sustentável em engenharia são mais críticos sobre o papel da tecnologia nuclear no espaço no desenvolvimento sustentável do que os seus estudantes e engenheiros profissionais são. Assim, cabe ao professor ajudar os alunos a identificar questões normativas no trabalho, que pareçam ser de natureza técnica e deve ajudar os alunos na construção de seu próprio argumento, o que exige um processo de aprendizagem ativo de ação e não de pregação.

O ensaio teórico (9) de Soriano-Díaz (2007) trouxe uma perspectiva de educação moral como formação de hábitos virtuosos. O texto selecionou alguns debates e autores representativos das tendências atuais na educação moral, considerando que a educação moral deve incluir tanto a educação em certos valores universais como a educação da racionalidade moral, a educação do afeto moral e a educação do caráter e da conduta. Com sua experiência no meio acadêmico espanhol, em seu ensaio, discutiu duas questões centrais: a) quais devem ser os caminhos e os conteúdos da educação cívica e ética, e b) que aspectos devem ser considerados para formar moralmente pessoas desde uma perspectiva integral.

A educação moral deve ser entendida, ao mesmo tempo, como "a implantação de princípios morais e a transmissão de hábitos virtuosos, processo que deve iniciar-se em idades bem pequenas" (SORIANO-DÍAZ, 2007, p.91).
Assim, a discussão apresentada pelo autor leva a perceber a educação moral como formação de hábitos virtuosos, o que remonta ao tempo de Aristóteles e que, ao mesmo tempo, tem sido revitalizada. Neste prisma, "para considerar moral um sujeito é preciso que ele mantenha uma linha de conduta virtuosa: que realize atos virtuosos e o faça habitualmente" (PUIG, 1998, p.62)

O artigo (6) de Cotton (2006) teve como objetivo investigar as crenças e práticas de três professores experientes em escolas secundárias inglesas, baseando-se a coleta de dados em entrevistas semiestruturadas, observação das aulas e transcrições de interação em sala de aula. A autora destacou a falta de compreensão por parte da população, de professores e mesmo da comunidade científica sobre os temas ambientais controversos. Sendo que os professores têm a difícil tarefa de apresentar questões extremamente complexas e emotivas para alunos de forma coerente e imparcial, o que não significa doutriná-los com 'slogans verdes'.

Os resultados apontaram para a não neutralidade do professor, posto que nenhum ensinamento é livre de valor. Ocorreu que, ao tentar ser neutro, o professor acabou gerando entre os alunos uma discussão sem fundamento, ou seja, sem gerar reflexão no grupo. Nesse sentido, era esperado que o aluno criticamente examine as informações. Assim, é improvável que o professore possa ensinar sobre um tema controverso, sem que de alguma forma expresse suas próprias atitudes sobre essa questão. Temas controversos, por definição, envolvem atitudes ou valores conflitantes", e sua natureza sugere que a neutralidade do professor seja impraticável e inútil pelo fato de não expor aos alunos uma gama de pontos de vista para que estes o analisem de forma crítica e responsável (COTTON, 2006).

Uma das implicações elencadas por Cotton (2006) se refere à urgente necessidade de formação de professores para o uso de diferentes estratégias para o ensino de temas controversos. Nesse sentido, encontra-se suporte nas práticas morais elencadas por Puig (2004) de reflexividade, de deliberação, as de virtude e as normativas.

Nesse mesmo sentido de construção de práticas morais, no Estado de Dakota do Sul - Estados Unidos da América, o artigo (7) de Bowne e Brokmeier (2008) salientou a importância de práticas deliberativas no contexto de Educação Infantil, tais como: "assembleia, resolução de conflitos, debate, resolução de dilema e dramatização" (PUIG, 2004, p.94).

Em todos os momentos retratados por Bowne e Brokmeier (2008), as crianças foram ouvidas, observando que todas as decisões estavam nas mãos delas, valendo-se de votação e de discussão em grupo para realizar escolhas, tanto para livros a serem lidos, como para o direcionamento de remontagem de um canto de aprendizagem, que no lugar da brincadeira de "casinha" se transformou em um espaço de dramatização de zoológico. Com base nessa decisão, as crianças se envolveram em pesquisas para conhecer mais sobre os animais, seus habitats, sons que emitem, hábitos de alimentação; sobre os 
funcionários de um zoológico e os itens a serem adquiridos para sua constituição, como, por exemplo, as jaulas. Este pode ser um exemplo positivo de currículo desenvolvido pelos próprios aprendizes.

Busca-se aqui apresentar o importante papel da Educação Ambiental na Educação Infantil, primando pelo desenvolvimento de valores éticos e estéticos em relação ao meio ambiente. Dos nove trabalhos levantados, cinco destinam suas discussões à Infância, sendo quatro destes associados às questões ambientais: (1) consumo, (3) meio ambiente e relação afetiva, (7) animais de zoológico e (8) meio ambiente.

\section{Conclusão}

Defende-se que um dos possíveis caminhos a ser escolhido para a Educação Ambiental na Educação Infantil é o da educação em valores ou educação moral. Os valores são entendidos como competências metacognitivas fundamentais para o desenvolvimento humano, posto que compreendem a principal força para mudar as atitudes tanto pessoais como profissionais para a construção de uma sociedade sustentável.

A melhoria da educação em valores pode estar associada à integração de uma perspectiva filosófica (ética) sobre as questões da sustentabilidade. O objetivo da "educação em valor" tem como ideal pedagógico melhorar a atitude responsável em relação ao uso do conhecimento científico, cabendo ainda compreender que os processos que as pessoas recorrem, quando confrontados com dilemas morais, mudam ao longo do tempo. Com base na perspectiva kohlberguiana, os indivíduos progridem, por etapas, os seus conceitos de justiça se expandem de egocêntrico para o da sociedade; a justiça se expande a partir de um sistema que serve a si mesmo, para aquela que serve aos amigos mais próximos e familiares para, posteriormente, também atender às comunidades maiores, incluindo estranhos.

Finalmente, cabe destacar a educação como uma possibilidade de incorporar valores éticos e estéticos, aqui especificamente, voltados para a temática ambiental, possibilitados pelo diálogo entre professores e crianças em idade pré-escolar no contexto formal de ensino.

\section{Referências}

BONOTTO, D.M.B. O trabalho com valores em educação ambiental: investigando uma proposta de formação contínua de professores. São Carlos: Universidade Federal de São Carlos, 2003.

BOWNE, M.; BROKMEIER, S. At the zoo: kindergartners reinvent a dramatic play area. Early Chilhood Res. Practice, v.10, n.2, 2008 .

BRASIL. Ministério da Educação. Diretrizes Curriculares Nacionais para a Educação Infantil - Resolução CNE/CEB n ${ }^{\circ} 5$, de 17 de dezembro de 2009. Brasília: MEC, 2009.

CARVALHO, J.S. Podem a ética e a cidadania ser ensinadas? Pró-Posições, v.13, p.157-178, 2002.

CARVALHO, L.M. A pesquisa no campo da formação e do trabalho docente relacionado com a temática ambiental. In:
DALBEN, A. et al. Coleção didática e prática de ensino: Convergências e tensões no campo da formação e do trabalho docente: Educação Ambiental, Educação em Ciências, Educação em Espaços não escolares e Educação Matemática. Belo Horizonte: Autêntica, 2010 p.67-88.

CARVALHO, L.M. A temática ambiental e o processo educativo: dimensões e abordagens. In: CINQUETTI, A.S.; LOGAREZZI, A. Consumo e residuos: fundamentos para o trabalho educativo. São Carlos: EdUFSCAR, 2006. p.19-41.

COTTON, D. Teaching controversial environmental issues: neutrality and balance in the reality of the classroom. Educ. Res., v.48, n.2, p.223-241, 2006. doi: 10.1080/00131880600732306

EL-BASSIOUNY, N.; TAHER, A.; ABOU-AISH, E. An empirical assessment of the relationship between character/ethics education and consumer behavior at the tweens segment: the case of Egypt. Young Consumers, v.12, n.2, p.159-170, 2011. doi: http://dx.doi. org/10.1108/17473611111141614.

LIMA RIBEIRO, M.S.; PROFETA, A.C.N.A. Programas de educação ambiental no ensino infantil em Palmeiras de Goiás: novos paradigmas para uma sociedade responsável. Rev. Eletr. Mestrado Educ. Amb., v.13, p.125-139, 2004.

MACEDO, E.; SOUSA, C.P. A pesquisa em educação no Brasil. Rev. Bras. Educ., v.15, n.43, p.166-176, 2010.

falseMAYHEW, J.M.; SEIFERT, T. A.; PASCARELLA, E.T. How the first year of college influences moral reasoning development for students in moral consolidation and moral transition. $J$. College Student Development, .v.53, n.1, p.19-40, 2012.

MEHMET, E. The effects of ecology-based summer nature education program on primary school students' environmental knowledge, environmental affect and responsible environmental behavior. Educ. Scie. Theory Practice,v.11, n.4, p.2233-2237, 2011.

MUIJEN, H. Integrating value education and sustainable development into a Dutch university curriculum. Int. J. Sustainability Higher Educ.. v.5, n.1, p.21-32, 2004. doi: http:// dx.doi.org/10.1108/14676370410512571.

falseMULDER. K.F. Don't preach. Practice! Value laden statements in academic sustainability education. Int. J. Sustainability Higher Educ., v.11, n.1, p.74-85, 2010. doi: http:// dx.doi.org/10.1108/14676371011010066

PAYA, M. Educación en valores para una sociedad abierta y plural: aproximación conceptual. Bilbao: Editorial Desclée de Brower, 2009.

PAYÁ SÁNCHEZ, M. Naturaleza de lós valores. In: OLIVEIRA, M.J.; FERREIRA, N.A. Educação e democracia: fundamentos teóricos para uma abordagem de valores. Salvador: EDUNEB, 2008. p. 41-64.

PAYÁ SÁNCHEZ, M. Educación en valores para una sociedad abierta y plural: aproximación conceptual. Bilbao: Desclée de Brower, 2000.

PAYNE, P.G. Framing Research: Conceptualization, Contextualization, Representation and Legitimization. Pesq. Educ. Amb., v.4, n.2, p.49-77, 2009.

PUIG, J.M. Práticas morais: uma abordagem sociocultural da educação moral. São Paulo: Moderna, 2004.

PUIG, J.M. A construção da personalidade moral. São Paulo: Ática, 1998.

SEGALÀS, J.; MULDER, K.F.; FERRER-BALAS, D. What do EESD "experts" think sustainability is? Which pedagogy is suitable to learn it? Int. J. Sustainab. Higher Educ., v.13, n.3, p.293304, 2012. doi:http://dx.doi.org/10.1108/14676371211242599

SENA, L.M.; BONOTTO, D.M. B.A dimensão valorativa da temática ambiental e o trabalho com valores em aulas de Ciências. Nuances Estud. Educ., v.23, n.24, p.181-201, 2012. 
BISSACO, C.M

SORIANO-DÍAZ, A. Los caminos de la educación civico-moral - Un debate permanente. Teoría Educ. Rev. Interunivers., v.19, p.73-97, 2007.
YARDIMCI, E.; LEBLEBICIOGLU, G. The effect of a nature camp on children's conceptions of nature. Int. Electr. J. Environ. Educ., v.2, n.2, p.89-102, 2012. 